\title{
The role of ejection fraction in varicose vein disease
}

\section{Recek ${ }^{1}$}

${ }^{1}$ Retired, formerly Department of Surgery, University Hospital, Hradec Kralove, Czech Republic. Address: Cestmir Recek, Mantlergasse 24, 1130 Vienna, Austria.

submitted: Feb 6, 2019, accepted: Feb 20, 2019, EPub Ahead of Print: Feb 20, 2019

Conflict of interest: None

DOI: 10.24019/jtavr.61 - Corresponding author: Dr. Cestmir Recek, cestmir@recek.at

(C) 2018 Fondazione Vasculab impresa sociale ONLUS. All rights reserved.

\begin{abstract}
The article addresses the significance of the parameter ejection fraction for evaluating therapeutic outcomes in varicose vein disease. Whereas in cardiology the ejection fraction is an excellent indicator of cardiac insufficiency, its validity for evaluating results after treatment of varicose veins is limited. This is because of the quite different situation in the heart and in varicose vein disease. Whereas the enlarged end-diastolic volume of the left ventricle is the consequence of decreased heart contractility, the amount of venous volume contained in varicose veins and the contractility of the calf musculature are not interrelated. Consequently, reduction of venous volume occurring after treatment of varicose veins fakes improved calf muscle performance; therefore, ejection fraction is an unsuitable parameter for evaluating results after varicose vein treatment.
\end{abstract}

Keywords ejection fraction; varicose veins; venous volume; saphenous reflux; venous hemodynamics.

The parameter ejection fraction provided by air plethysmography has been used for evaluation of calf pump performance resulting from the treatment of varicose veins ${ }^{1}$; it was borrowed from cardiology. In cardiology, it is the fraction between the ejected volume and the end-diastolic volume of the left ventricle; the normal value ranges from $55 \%$ to $70 \%$. Heart insufficiency is characterized both by the dilatation of the left ventricle inducing enlarged end-diastolic volume and the simultaneous reduction of the ejected volume; both phenomena contribute to the diminution of the ejection fraction. It follows that the parameter ejection fraction in cardiology is a sensitive indicator of cardiac insufficiency.

Unfortunately, the situation in varicose vein disease is quite different. The parameter ejection fraction in varicose veins disease is calculated from the ejected volume and the venous volume, both obtained by air plethysmography: EF $=\mathrm{EV} / \mathrm{VV}$. Although the calf musculature operates similarly to the left ventricle - it is able to increase the systolic pressure in deep lower leg veins by 53-128 mm Hg (mean $75 \mathrm{~mm} \mathrm{Hg}$ ) over the level of the hydrostatic pressure ${ }^{2}$ - several conditions differ considerably. In varicose vein disease the contractile force of the calf musculature is not depressed; in many cases it may be even strengthened. The other discrepancy concerns the venous volume contained in varicose veins; its amount and the contractility of the calf musculature are not interrelated. This is the most pregnant contrast to the condition in the left ventricle. Because the ejection fraction in varicose vein disease depends on the amount of venous volume in varicose veins, reduction of this venous volume, which is even the goal of the therapeutic treatment, improves artificially the value of ejection fraction and fakes improved calf pump performance. Therefore, comparison of ejection fraction before and after treatment yields misleading information. In addition, the situation is yet more confusing because the ejected volume might be likewise influenced. Strong saphenous reflux impacts on the size of all veins participating in the so called "Trendelenburg's private circulation": not only the incompetent saphenous system but also calf perforators and the concerned segments of the deep veins enlarge distinctly. Enlarged deep lower leg veins contain more blood. As the contractility of the calf muscles in varicose vein disease isn't usually diminished, it can be deduced that the calf muscle pump is able to produce increased ejected volume in the presence of increased preload. After elimination of saphenous reflux the size of the afflicted venous segments inclusive of deep lower leg veins diminishes significantly in the course of 
follow-up ${ }^{3-6}$; the consequence might be diminished ejected volume, which would diminish the post-treatment ejection fraction. Nonetheless, a large discrepancy remains between the markedly reduced venous volume in the treated varicose veins and the possibly slightly reduced ejected volume; consequently, the post-treatment value of the ejection fraction falsely indicates improved calf pump performance. It follows that the parameter ejection fraction is unsuitable for evaluating the results after treatment of varicose veins.

The ejection fraction in varicose vein disease might be useful in situations where the venous volume remains unaffected, e.g. when comparing the effectivity of provocations tests in the same patient ${ }^{7}$.

\section{Conclusion}

Whereas ejection fraction is a sensitive indicator of cardiac insufficiency, in varicose vein disease this parameter yields fallacious information about improved calf pump performance after varicose vein treatment. This is because the venous volume contained in varicose veins bears no relationship to the calf muscle contractility. Therefore, ejection fraction is an unsuitable parameter for comparing results after varicose vein treatment. It may be reasonably used only in cases where the venous volume remains unchanged.

\section{References}

1) Park UJ, Yun WS, Lee KB, et al. Analysis of the postoperative hemodynamic changes in varicose vein surgery using air plethysmography. J Vasc Surg 2010; 51: 634-638.

2) Arnoldi CC. Venous pressure in the leg of healthy human subjects at rest and during muscular exercise in nearly erect position. Acta Chir Scand 1965; 130: 573-583.

3) Stuart WP, Adam DJ, Allan PL, et al. Saphenous surgery does not correct perforator incompetence in the presence of deep venous reflux. J Vasc Surg 1998; 28: 834-838.

4) Recek C, Karisch E, Gruber J. Diameter alterations of calf perforators and deep veins in the lower leg after abolition of saphenous reflux (German). Phlebologie 2000; 29: 37-40.

5) Al-Mulhim AS, El-Koseiny H, Al-Mulhim FM, et al. Surgical correction of main stem reflux in the superficial venous system: does it improve the blood flow of incompetent perforating veins? World J Surg 2003; 27: 793-796.

6) Gohel MS, Barwell JR, Wakely C, et al. The influence of superficial venous surgery and compression on incompetent calf perforators in chronic venous leg ulceration. Eur J Vasc Endovasc Surg 2005; 29: 78-82.

7) Lattimer CR, Franceschi C, Kalodiki E. Optimizing calf muscle pump function. Phlebology 2018; 33: 353-360. 